\title{
Violencias, omisiones y estructuras que enfrentan las personas LGBTI
}

\author{
Violence, Omissions and Structures Faced by LGBTI Community \\ Individuals \\ Violências, omissões e estruturas que enfrentam as pessoas LGTBI
}

\section{MANUEl FERNANDo QUinCHE RAMÍREZ*}

FECHA DE RECEPCIÓN: 11 DE FEBRERO DE 2016. FECHA DE ACEPTACIÓN: 14 DE MARZO DE 2016

DOI: DX.DOI.ORG/10.12804/ESJ 18.02.2016.02

Para citar este artículo: Quinche, M. (2016). Violencias, omisiones y estructuras que enfrentan las personas LGBTI. Estudios Socio-Jurídicos, 18(2), 49-87. Doi: dx.doi.org/10.12804/esj 18.02.2016.02

\section{RESUMEN}

Este escrito tiene como punto de partida la interpretación y el diagnóstico contenido en el Informe de la Comisión Interamericana denominado "Violencia contra personas LGBTI". Desde allí se explicitan otras formas de violencia, entre ellas, la violencia institucional que se origina en el incumplimiento de las obligaciones de respeto y garantía sobre los derechos de esas personas. Además, se trabaja el tema de las omisiones legislativas y convencionales e identifica algunas estructuras tradicionales de dominio que impiden el reconocimiento y la protección de los derechos de esa comunidad.

Palabras clave: discriminación, personas LGBTI, violencia por prejuicio, orientación sexual, identidad de género, expresión de género, omisión legislativa, omisión convencional, esfera de lo indecidible.

* Doctor en Derecho. Profesor de Derecho Constitucional, Universidad del Rosario. Correo electrónico: manuelf.quinche@urosario.edu.co 


\section{ABSTRACT}

As starting point, this article interprets and makes a diagnosis of the content in the InterAmerican Commission report called "Violence against LGBTI people". From there it explicit other forms of violence such as the institutional violence, which begins with the breaching of the obligations to respect and the warranty over those people's rights. Additionally this text works on the issue of legislative and conventional omissions, and identifies some of the traditional domain structures, those that impede the recognition and protection of this community's rights.

Keywords: discrimination, LGBTI people, prejudice violence, sexual orientation, gender expression, legislative omission, conventional omission, the sphere of the undecidable.

\section{RESUMO}

Este escrito tem como ponto de partida a interpretação e o diagnostico contido no Informe da Comissão Interamericana denominado Violência contra pessoas LGTBI. Desde ali se explicitam outras formas de violência, entre elas, a violência institucional que se origina no incumprimento das obrigações de respeito e garantia sobre os direitos dessas pessoas. Além disso, trabalha-se o tema das omissões legislativas e convencionais e identifica algumas estruturas tradicionais de domínio que impedem o reconhecimento e a proteção dos direitos dessa comunidade.

Palavras- chave: Discriminação, pessoas LGTBI, violência por prejuízo, orientação sexual, identidade de gênero, expressão de gênero, omissão legislativa, omissão convencional, esfera do indizivel. 
El hecho cierto y documentado por la Comisión Interamericana de Derechos Humanos (en adelante, la Comisión Interamericana) es el de una intensa y generalizada violencia de género cernida sobre las personas LGBTI en los países de América Latina, que se superpone a la histórica violencia de género ejercida sobre las mujeres. Esta ha dado lugar a la expedición de algunas leyes antidiscriminación y a la tipificación del "feminicidio" como una conducta delictiva autónoma, pero ha guardado silencio alrededor de las personas LGBTI.

Las conclusiones del Informe de la Comisión Interamericana son tan obvias como preocupantes, en el sentido de que evidencian diversas formas de violencia generalizada en contra de esas personas, que tiene en la base una historia local de intolerancia sobre grupos sociales discriminados. Desde esa perspectiva, el Informe concluye:

[...] que el contexto generalizado de discriminación social e intolerancia respecto de esta diversidad, aunado a la ausencia de investigaciones efectivas, y la falta de un abordaje diferenciado para prevenir, investigar, juzgar, sancionar y reparar los crímenes cometidos contra personas LGBTI, son elementos que conducen a que se condone y tolere esta violencia, lo que resulta en impunidad y repetición (Comisión IDH, 2015, párr. 508).

Como punto de partida se tienen la interpretación y el diagnóstico dispuestos en el Informe de la Comisión Interamericana y se afirma que las diversas formas de violencia que se desatan en contra de las personas LGBTI también corresponden a la respuesta de sectores sociales que entienden que el reconocimiento y la defensa de esos derechos implican la remoción de estructuras de dominio consolidadas alrededor de las cuales fueron construidos los Estados de la región, como el dominio clerical, el dominio militar, el registro y la estructura de la sociedad letrada, que operó transversalmente a las anteriores.

Para desarrollar el tema se procederá de la siguiente manera: en primer lugar, se hace una presentación general del Informe sobre violencia de la Comisión Interamericana, para sostener que buena parte de esa violencia es institucional, en la medida en que corresponde a acciones u omisiones de autoridades públicas de distinto rango. En segundo término, se explicita una forma pasiva de violencia institucional que consiste en el incumplimiento 
de las obligaciones de regulación y garantía que tiene el Estado sobre los derechos, visible bajo la forma de omisiones legislativas y de omisiones convencionales. Por último, se describen los elementos contenidos en las estructuras de dominio señaladas y los intentos de su remoción.

Este escrito tiene como recursos básicos el Informe sobre violencia de la Comisión Interamericana y el Derecho Judicial, en tanto registran casos documentados y verificables, puestos en relación con el caso colombiano.

\section{La violencia generalizada contra las personas LGBTI en América Latina}

En noviembre de 2015, la Comisión Interamericana publicó el documento titulado Violencia contra personas lesbianas, gais, bisexuales, trans e intersexuales en América, que consiste en la presentación de un Informe acerca de la violencia física y generalizada de la que son víctimas las personas con orientaciones sexuales, identidades y expresiones de género no normativas o cuyos cuerpos varían del estándar corporal femenino o masculino en América, denominadas personas LGBTI.

Dicho Informe es el resultado final de muchos años de trabajo alrededor de esas personas, sus derechos y las violencias a las que han sido sometidas. Como momentos relevantes de esa actividad se señalan la expedición de la Resolución 2435 de junio 3 de 2008, adoptada por la Asamblea General de la Organización de Estados Americanos (OEA), titulada Derechos humanos, orientación sexual e identidad de género; la adopción en 2010 del Plan de acción estratégico 2011-2015, que incluyó como uno de sus componentes el asunto de los derechos de las personas LGBTI; la creación en noviembre de 2011 de la Unidad para derechos de personas LGBTI, adscrita a la Secretaría Ejecutiva de la Comisión; la designación en 2012 de una comisionada especial para la Unidad LGBTI y el establecimiento el 8 de noviembre de 2013 de la Relatoría sobre los derechos de las personas lesbianas, gais, bisexuales, trans e intersexuales, que entró en funciones en enero de 2014 y el 17 de diciembre de 2014 publicó un documento titulado Una mirada a la violencia contra personas LGBTI, que registra actos de violencia perpetrados en la región en contra de esa comunidad entre 
el 1 de enero de 2013 y el 31 de marzo de 2014 y es uno de los soportes fundamentales del Informe final (Comisión IDH, 2014).

\subsection{Estructura y componentes del Informe sobre violencia contra personas $L G B T I$}

El Informe fue dispuesto en siete capítulos desarrollados en 320 páginas. El Capítulo I, denominado "Introducción", describe los antecedentes del Informe y la metodología adoptada durante las fases de investigación y escritura; además, precisa algunas expresiones decisivas en el tratamiento del tema, como los términos "orientación sexual", "identidad de género" y "expresión de género", definidos desde los principios de Yogyakarta (Principios de Yogyakarta, 2007). El Capítulo II, "Comprendiendo y definiendo la violencia contra las personas LGBTI", consiste en un estudio de las características de la violencia padecida por esa comunidad. Su punto de partida es la consideración del lenguaje social en sus notas heteronormatividad, cisnormatividad y binarios de sexo y género, adoptados como elementos clasificatorios del lenguaje social, institucional y jurídico, que han propiciado la construcción de estereotipos usados para discriminar y victimizar y ha dado lugar a la "violencia por prejuicio", una forma específica de violencia de la que son víctimas las personas LGBTI. El Capítulo III, "Impacto de las leyes que criminalizan a las personas LGBTI en la violencia". Si el capítulo anterior analizaba los elementos desencadenantes y concurrentes con la violencia física, en este se examina la violencia jurídica, la normativa, la que desatan las legislaciones que castigan y persiguen la vida privada y los usos del cuerpo, bajo la excusa de defender la decencia, la moral pública y otras cosas similares.

El Capítulo IV es descriptivo, analítico y doloroso y se titula "Formas y contextos de la violencia contra las personas LGBTI". Allí hay análisis de contexto, que constituyen una de las contribuciones más valiosas del Sistema Interamericano en la región y tienen como premisa que la violación masiv a de derechos o la que recae sobre grupos concretos de personas corresponde a contextos específicos de victimización. ${ }^{1}$ Se dispusieron tres zonas

\footnotetext{
El análisis de contexto se trasplantó con éxito desde los órganos del Sistema Interamericano a los órganos judiciales de los Estados parte en la Convención Americana. En el caso de Colombia,
} 
temáticas. La primera de ellas identifica las diversas formas de violencia que se ejercen sobre esas personas, señala a la crueldad como un elemento común y explica las causas de su invisibilidad. La segunda individualiza los derechos más violados, mientras la tercera trabaja el tema del discurso del odio y el de incitación a la violencia. El Capítulo V se denomina "Violencia e intersección con otros grupos". Introduce un recurso metodológico, la interseccionalidad, que permite enriquecer el análisis al cruzar dos elementos: el objeto de la victimización (las orientaciones sexuales e identidades de género no normativas y las variaciones en las características de sexo) con los factores recurrentes con la victimización (etnia, raza, género, sexo, situación migratoria, ser defensor de derechos humanos y condición de pobreza). Como lo expresa el Informe, es necesario resaltar la relación entre violencia y discriminación, en el despliegue de una marginación histórica y estructural ejercida sobre grupos que padecen "un ciclo continuo de violencia y discriminación causado por la impunidad y la falta de acceso a la justicia" (Comisión IDH, 2015, párr. 166).

El Capítulo VI, "Respuesta estatal frente a la violencia y acceso a la justicia", explicita el contenido puntual de las obligaciones de respeto y garantía sobre los derechos (Artículo 1 de la Convención Americana sobre Derechos Humanos, en adelante, la Convención Americana) y la obligación de adoptar disposiciones de Derecho interno (Artículo 2 de la Convención Americana). Puesto que las personas LGBTI son víctimas de una violencia tolerada por los Estados parte en la Convención, es necesario precisar el contenido de las obligaciones que deben ser satisfechas por los Estados, las que son presentadas en tres grupos: las obligaciones de prevención; la obligación de investigar, juzgar y sancionar crímenes cometidos contra esas personas y las obligaciones de reparación.

El texto culmina con el Capítulo VII, titulado "Conclusiones y recomendaciones". Estas últimas son presentadas en dos grupos. El primero corresponde a las recomendaciones generales, dirigidas al poder Ejecutivo y al poder Legislativo y las relacionadas con el acceso a la justicia. El

\footnotetext{
la determinación de los contextos como elemento metodológico para la decisión judicial viene siendo implementada, cuando menos, en cinco escenarios: la Fiscalía General de la Nación, la Sala de Casación Penal de la Corte Suprema de Justicia, la Corte Constitucional, la Jurisdicción de Justicia y Paz dispuesta por la Ley 975 de 2005 y la Jurisdicción de Restitución de Tierras, creada por la Ley 1448 de 2011.
} 
segundo grupo es el de las recomendaciones específicas, sectorizadas en dos segmentos: las recomendaciones específicas según los contextos de violencia, relacionadas con la libertad de expresión, las fuerzas de seguridad del Estado, la salud y la educación; y las recomendaciones específicas según grupos particulares de personas LGBTI, referidas a los pueblos indígenas, las mujeres, las personas en el contexto de la movilidad humana, niños, niñas y adolescentes, las defensoras y los defensores de derechos humanos, afrodescendientes y otras personas afectadas por la discriminación racial, las que viven en la pobreza y las privadas de la libertad.

\subsection{Algunos elementos relevantes del informe}

En el plano general, el Informe de la Comisión es el primer trabajo sistemático e integral que se hace en el continente sobre la violencia que se ejerce sobre las personas LGBTI, desde la institucionalidad y con una metodología definida. Sus conclusiones y recomendaciones son materia confiable para cada uno de los Estados parte en la Convención, cuando menos en tres planos: en el plano social, en relación con las prácticas ciudadanas; en el plano institucional, con el diseño y ejecución de las políticas públicas de los Estados y, en el plano legislativo, con los déficit normativos, en especial los de la legislación criminal. Sin embargo, como elemento deficitario, podría señalarse que el estudio pudo abarcar otros escenarios que han generado y repetido imágenes estereotipadas de las personas LGBTI, como los medios de comunicación, las instituciones educativas, las iglesias y confesiones religiosas, los sindicatos y las asociaciones de trabajadores y las asociaciones de residentes o de vecinos, entre otros.

La conclusión general del Informe gira alrededor de la tesis de la violencia generalizada contra las personas LGBTI, presentada en los siguientes términos:

518. Las sociedades en el continente americano están dominadas por principios de heteronormatividad, cisnormatividad, y los binarios de sexo y género. Además, existe una amplia y generalizada intolerancia e irrespeto hacia las personas LGBTI o aquellas percibidas como tales, lo cual se suma al fracaso de los Estados en adoptar medidas efectivas para investigar y castigar efectivamente la violencia por prejuicio. En este informe, la $\mathrm{CIDH}$ 
concluye que el contexto generalizado de discriminación social e intolerancia respecto de esta diversidad, aunado a la ausencia de investigaciones efectivas, y la falta de un abordaje diferenciado para prevenir, investigar, juzgar, sancionar y reparar los crímenes cometidos contra personas LGBTI, son elementos que conducen a que se condone y se tolere esta violencia, lo que resulta en impunidad y repetición (Comisión IDH, 2015, párr. 44).

Uno de los grandes aciertos del Informe es la identificación de los diversos tipos de violencia que se ejerce sobre esta comunidad, entre los que cabe destacar:

La violencia física, que es el dato inmediato de la victimización. Documenta casos denunciados y no denunciados de violencia física padecidos por personas con orientaciones sexuales, identidades y expresiones de género no normativas o cuyos cuerpos varían del estándar corporal femenino y masculino en América. Ahora bien, si el punto de partida es la violencia física como suceso, ella desenmascara o pone de presente otros tipos de violencia.

La violencia social, ligada al contexto de las violaciones de los derechos de las personas LGBTI. En esta dimensión, la violencia es descrita y asumida como un fenómeno complejo que ofrece muchas aristas. Esto es muy importante, pues la violencia contra esas personas ha sido intencionalmente asumida como un fenómeno simple, constituido por la sucesión o la recurrencia de actos individuales o de fenómenos aislados, sometidos a la respuesta lenta e ineficaz del proceso penal.

La indagación alrededor de la violencia social da lugar al concepto clave del Informe: el de violencia por prejuicio contra las orientaciones sexuales y las identidades de género no normativas, que origina los crímenes por prejuicio y:

[...] constituyen racionalizaciones o justificaciones de reacciones negativas, por ejemplo, frente a expresiones de orientaciones sexuales o identidades de género no normativas. Tal violencia requiere de un contexto y una complicidad social, se dirige hacia grupos sociales específicos, tales como las personas LGBT y tiene un impacto simbólico (Comisión IDH, 2015, párr. 44). 
Una cuarta forma de violencia es la violencia correctiva, que se manifiesta en la "violación correctiva" y la "violencia sexual correctiva", identificadas y denunciadas en el Informe como la violencia sexual (violaciones o actos sexuales violentos) que asumen la forma de un castigo a las personas que desafían las normas tradicionales del género en razón de su orientación sexual, identidad o expresión de género. La violencia correctiva es una de las formas más perversa de violencia, en tanto se despliega como un castigo sobre el cuerpo y la propia sexualidad, con la idea de "corregir" o encausar las desviaciones.

Por último, se tiene la violencia médica y la que se ejerce en la prestación de los servicios de salud. Respecto a la primera, el Informe documenta en especial las intervenciones médicas sobre los cuerpos de las personas intersexuales, también ejercidas con fines "correctivos" o de "normalización" y con la complicidad de los familiares de las víctimas. Respecto al sistema de salud la victimización es doble, pues a la crisis permanente de los sistemas de salud de la mayoría de los países de América Latina, se suman acciones concretas contra los pacientes LGBTI, como la interposición de barreras de acceso al servicio, la violencia explícita sobre el paciente, el desprecio y el uso de lenguaje ofensivo y mecanismos de exclusión en casos de prestación del servicio por comunidades religiosas.

Tras presentar la estructura general del Informe de la Comisión Interamericana y describir las formas de violencia allí identificadas, se procede ahora al tratamiento de una forma específica de violencia, la violencia institucional de tipo normativo, que pone de presente el fenómeno de las omisiones legislativas y convencionales sobre los derechos de las personas LGBTI.

\section{La violencia institucional normativa sobre las personas LGBTI. La falta de regulación y la ausencia de garantías. Omisiones legislativas y convencionales}

De acuerdo con el Informe de la Comisión Interamericana, la violencia que se ejerce sobre las personas LGBTI ofrece múltiples facetas y modalidades y es propiciada, en buena parte, por legislaciones que persiguen y criminalizan la vida privada y las preferencias sexuales, así como por 
normas que, con la excusa de la decencia, la pulcritud o la moral pública, marginan y castigan las orientaciones sexuales, las expresiones de género y sus manifestaciones.

En dicho escenario ha sido instalada una forma pasiva de violencia institucional, pero al fin violencia, que consiste en incumplir las obligaciones de regulación y de garantía sobre los derechos de las personas LGBTI. En Colombia, al igual que en otros países de la región, el Congreso y la Presidencia expiden normas de fomento de la actividad minera, destrucción de los recursos naturales, protección de la inversión extranjera, comercio electrónico, régimen fiscal y de aduanas, criminalización de la protesta ciudadana y protección a multinacionales y entidades financieras, pero se abstienen de expedir aquellas que reconozcan los derechos de las personas LGBTI y las doten de instrumentos administrativos y judiciales que les permitan defender sus derechos.

Los jueces de la jurisdicción constitucional han sido forzados a asumir la tarea del reconocimiento y la defensa de tales derechos, en nombre del valor normativo de la Constitución, la defensa de los derechos fundamentales de las minorías y la realización de lo que Ferrajoli (2000) denomina la democracia constitucional, que es sustantiva y no solo plebiscitaria. De estos elementos, es decir, del incumplimiento de las obligaciones del Estado sobre los derechos, de la democracia constitucional y de las omisiones legislativas y convencionales, es que se ocupa esta sección.

\subsection{El incumplimiento de las obligaciones de regulación y garantía sobre los derechos de las personas LGBTI como forma de violencia institucional}

En torno a este tema es necesario formularse y contestar varias preguntas. En materia de derechos fundamentales y de ejercicio de la función legislativa, el Congreso, como órgano representativo y legislativo que era regido por la "soberanía parlamentaria", ¿puede hacer lo que políticamente quiera o debe hacer lo que jurídicamente debe? Dentro de esta misma perspectiva, cuando el Congreso no cumple con las obligaciones de regulación sobre los derechos, ¿qué deben hacer las personas y las otras instituciones?, ¿esperar hasta que el Congreso decida cumplir con sus obligaciones o deben 
contribuir a la realización de los derechos desde el ejercicio de sus propias facultades y competencias?

La tesis que aquí se plantea es que la realización de la democracia constitucional es la prioridad de todas las personas y de todas las instituciones y cuando un órgano se resiste al cumplimiento de sus funciones para la realización de los derechos y de la democracia, corresponde a las otras instituciones, en especial a los jueces y a la ciudadanía, la tarea de propiciar la realización de los derechos.

El punto de partida de esta situación está en la reformulación hecha durante la última parte del siglo XX, acerca de las obligaciones que tiene el Estado respecto a los derechos de las personas, ya referida en un texto anterior, (Quinche, 2013), que resulta aquí vigente.

Un problema central de los sistemas latinoamericanos está en que los derechos humanos no son tratados como derechos plenos, sino como simples declaraciones o aspiraciones. En sentido contrario, es necesario insistir en el valor normativo de esos derechos y puntualizar las obligaciones directas que tienen los Estados frente a los mismos. Abramovich y Courtis (2006) señalan que todo derecho debe ser considerado como un complejo de obligaciones positivas (deberes de "hacer" para efectivizar el contenido de los derechos) y negativas (deberes de "abstención" para evitar la violación de los derechos), del que se derivan cuatro clases de obligaciones directas de los Estados:

Obligaciones negativas o deberes de respeto y de abstención

Se trata de obligaciones de contenido negativo e implican que el Estado no debe vulnerar con su acción el goce y el ejercicio de los derechos. De esta manera, el Estado debe abstenerse de articular políticas o acciones que impliquen la violación directa o indirecta de los derechos humanos. Así, este no puede practicar el homicidio selectivo, desaparecer personas y sus fuerzas de seguridad o de policía no pueden hacer persecución u hostigamiento de los homosexuales, las lesbianas o los transexuales. Dentro de la misma comprensión, no debe impedir el ejercicio de las libertades del plano social, como los derechos a la libertad de reunión o de asociación y debe respetar el derecho a la protesta. Por tradición, se había entendido que el Estado era legítimo si respetaba los derechos de las personas: hoy eso no 
es suficiente, puesto que es necesario que cumpla también las obligaciones positivas o de prestación, las de regulación y las de garantía.

\section{Obligaciones positivas o deberes de prestación y protección}

No basta con que el Estado se abstenga de vulnerar o de afectar los derechos de las personas. Es necesario además que el Estado facilite, propicie y haga cuanto esté a su alcance para que las personas puedan gozar de sus derechos con acciones encaminadas a ello. Por ejemplo, si se trata de derechos sociales, el Estado debe diseñar políticas públicas eficaces y a la vez respetuosas de los derechos sociales fundamentales, que permitan la realización del derecho a la salud, al trabajo, a la educación, etc. Dentro de esta dimensión y para el caso específico de las personas LGBTI, es obligación del Estado diseñar e implementar políticas públicas de inclusión laboral, educativa y de seguridad social para esa población, históricamente excluida de todas las formas de asistencia y protección.

\section{Obligaciones de regulación}

El Estado tiene además la obligación de regular los derechos por medio de normas jurídicas. Esta obligación es muy importante, en especial en América Latina, donde el contenido de los derechos ha sido abandonado a la actividad del legislador. Aquí es necesario precisar que se refiere a una obligación positiva, encaminada a lograr la efectivización del derecho por medio de normas y no a impedir su realización, con regulaciones que hagan inane su contenido.

Para tratar los eventos de incumplimiento de las obligaciones de regulación han surgido los conceptos jurídicos de omisión legislativa y de omisión convencional. En Colombia, la jurisprudencia constitucional ha estructurado el cargo de inconstitucionalidad por omisión legislativa, al señalar:

[...] el legislador incurre en omisión legislativa relativa cuando ha regulado de manera insuficiente o incompleta un mandato constitucional; $\mathrm{o}$ cuando dicha insuficiencia de regulación (omisión de una condición o un ingrediente que de acuerdo con la Constitución, sería exigencia esencial 
para armonizar con ella) o incompleta reglamentación, conduce a la violación del derecho a la igualdad (Corte Constitucional, 2007).

Un caso clásico de incumplimiento de las obligaciones de regulación por parte del Estado es el relacionado con los derechos de las personas LGBTI en Colombia. Respecto a ellos, la Corte Constitucional se vio forzada a declarar el déficit de protección sobre esos derechos en virtud de la incuria del Congreso, la resistencia de los cristianos y la mojigatería de las personas decentes, como quedó consignado, entre muchas otras, en la Sentencia C-577 de 2011, relacionada con el derecho al matrimonio de las parejas del mismo sexo (Corte Constitucional, 2011).

\section{Obligaciones de garantía o de satisfacción}

En cuarto lugar, el Estado está obligado al cumplimiento de las obligaciones de garantía, que implican que el Estado debe asegurar el ejercicio del derecho cuando el titular no puede hacerlo por sí mismo. Abramovich y Curtis (2006) señalan:

Así, debe asegurar el acceso a servicios de salud y educación, asegurar el acceso a la alimentación, facilitar las posibilidades de expresión de distintos grupos sociales, fomentar el acceso al consumo de productos básicos, sanear títulos de propiedad, simplificar los trámites que permitan asociarse o casarse, proveer de asistencia legal a quienes no puedan pagar un abogado, mejorar el acceso a la justicia de grupos postergados, etcétera (p. 27).

En el plano de la Constitución, "las garantías constitucionales constituyen medios tendientes a asegurar la protección de los derechos y a afianzar la seguridad jurídica. Actúan como instrumentos para contener el poder" (Cassagne, 2009, p. 94). En su faceta judicial, las obligaciones de garantía incluyen el derecho a tutela judicial efectiva, así como el derecho a jurisdicción y procedimiento, todo ello en la necesidad de cumplir el derecho al recurso judicial efectivo como componente del debido proceso judicial, que es una de las necesidades más sentidas de las personas LGBTI. 


\subsection{La democracia constitucional, los derechos de las personas LGBTI y la esfera de lo indecidible por el Congreso y por las mayorías}

La expresión "democracia" ha sido objeto de innumerables usos, estudios y clasificaciones, que van desde los simples, de los políticos y de los ciudadanos, hasta los sofisticados, de los académicos o de los filósofos. Igual acontece con los estudios y las clasificaciones de la democracia dispuestos por los historiadores y los filósofos políticos y hoy incrementados por los señores de la ciencia política o Sciences Po, como les gusta llamarlos ahora. El punto es que alrededor de dicha expresión ha sobrevenido una gran complejidad, patente en la multiplicación de conceptualizaciones, estudios y clasificaciones.

Un modo posible de entrar en el asunto consiste en diferenciar entre el concepto de democracia, las concepciones acerca de la democracia y los modelos de democracia (Arango, 2012).

El concepto de democracia es relativamente unívoco y está relacionado con el autogobierno del pueblo, con la deliberación y la decisión de los ciudadanos alrededor de sus propios asuntos y los de su comunidad, lo que les permite decidir la ley y quedar sometidos a ella. Sin embargo, como señala Arango (2012), el asunto se complica, al pensar en el papel y en las actuaciones del pueblo en el momento de deliberar y al considerar los canales que utiliza para materializar sus decisiones. Alrededor de esos escenarios surgen las concepciones acerca de la democracia que se despliegan con diversos nombres, entre ellos, los de democracia representativa, democracia partidista, democracia parlamentaria, democracia deliberativa y, más reciente, la democracia incluyente, determinada por la necesidad de incluir dentro del juego democrático a sectores excluidos como los grupos étnicos, las minorías culturales, las mujeres, los migrantes y las personas de diversa orientación sexual como las LGBTI.

Presentados el concepto y las concepciones de democracia, el autor aborda el asunto de los modelos de democracia más influyentes en el siglo XX y diferencia entre los modelos normativos y los modelos derivados de democracia.

Los modelos normativos de democracia son tres: la democracia liberal, que asume como punto central a la persona humana individual; la democracia republicana, cuyo eje es la sociedad; y la democracia deliberativa, 
que trabaja en torno al proceso político y a la toma de decisiones. Ahora bien, puesto que en Colombia y la región lo que se ha pretendido es el establecimiento y realización de la democracia liberal, la referencia aquí se limita a esta.

La democracia liberal es la más prestigiosa. De hecho, los libros de texto y los discursos de los políticos y de los académicos hablan de las democracias liberales y de las constituciones liberales como los elementos centrales de la institucionalidad en América Latina. De acuerdo con Arango (2012), la democracia liberal descansa sobre:

[...] una idea de sociedad construida por acuerdos contractuales que a su vez determinan la comprensión del proceso político. Según este enfoque, en el proceso político prima el principio de la mayoría, según el cual las decisiones de interés general se adoptan mediante el criterio de lo que potencia, maximiza u optimiza el bienestar de la población según la decisión autónomamente expresada de sus integrantes (p. 66).

De acuerdo con el autor, este modelo asume como premisa el carácter racional de individuo, la titularidad de los derechos individuales - entre ellos, el de la autonomía de la voluntad-, analogiza el modelo político con el de las relaciones del mercado y se asocia con otro modelo, el de la democracia procedimental, que plantea la necesidad de la adopción de reglas para la conformación de la organización política y la organización social, entre las que se cuentan las reglas electorales.

Al lado de los modelos normativos, Arango (2012) identifica los modelos derivados de democracia, más operativos, que son aplicaciones concretas de modelos ideales y también pueden ser entendidos como derivaciones de los modelos normativos ya expuestos. Allí se encuentran la democracia mayoritaria, la democracia mediática y la democracia social, que es la opción del autor.

La democracia mayoritaria es presentada como la forma extrema del modelo de la democracia liberal y coincide en los elementos descriptivos con lo que Ferrajoli (2000) llama democracia plebiscitaria. Se trata de un modelo agregativo, en el que tan solo cuentan los votos y los apoyos de las mayorías. Se basa en una comprensión realista y pragmática de la democracia y de la institucionalidad, en la que lo único que importa es ganar 
los certámenes electorales para instalar la institucionalidad y la legitimidad institucional de lo que se decida. Como dice el autor:

En este escenario ningún papel juegan las minorías o el disenso en la conformación de la voluntad general. La confianza en el modelo se explica por la idea utilitaria de que el bienestar general está mejor representado cuando los parlamentarios o los congresistas se toman en serio la voluntad de la mayoría (Arango, 2012, p. 66).

Dentro de esta comprensión, lo político y lo jurídico estarían en la órbita de "lo decidible" por las mayorías, quienes estarían en la mejor posición de hacer las exclusiones que quieran, como ha acontecido con los derechos de las personas LGBTI.

El segundo modelo alternativo es el de la democracia mediática, que experimenta una gran expansión en la actualidad, debido al inmenso poder de los medios de comunicación y a la creciente influencia de las redes sociales. Este modelo opera como elemento concurrente y complementario de la democracia mayoritaria, desde los sentimientos de aceptación y solidaridad de las personas. Es un modelo peligroso de democracia, en tanto es perfecto para establecer diferencias de trato y exclusiones, máxime si se considera que los dueños de los medios de comunicación y del poder mediático son los grupos económicos y la empresas multinacionales y que, en el plano estatal, el dominio corresponde a la coalición de Gobierno impuesta por las mayorías electorales.

Por último, Arango (2012) hace su propuesta de la democracia social como una alternativa a los modelos realistas y descarnados de las democracias mayoritaria y mediática. De acuerdo con el autor:

Este modelo pretende realizar integralmente los derechos humanos, no sólo las libertades clásicas y los derechos políticos, sino particularmente los derechos sociales, ideal al que se ha tendido por las democracias europeas bajo la vigencia del estado social de derecho en la segunda mitad del siglo XX (p. 77).

Sostiene también que este modelo es el que mejor se acompasa con la fórmula del Estado social, constitucional y democrático de Derecho. 
En la misma línea de lo que es la democracia para Arango puede ser ubicado el pensamiento de Ferrajoli (2000), quien desde la institución del control constitucional, también asume la distinción entre una democracia formal, mayoritaria o plebiscitaria y una democracia constitucional, en la medida en que el control de constitucionalidad tan solo puede operar a cabalidad en el escenario de la democracia constitucional, en donde las mayorías no pueden ejercer su poder en razón del número, sino que deben enfrentar a la Constitución como límite formal y material de su poder.

Para Ferrajoli (2000), la democracia formal, mayoritaria o plebiscitaria consiste en:

[...] la omnipresencia de la mayoría, o bien de la soberanía popular. De allí se sigue una larga serie de corolarios: la descalificación de las reglas y de los límites al poder ejecutivo expresado por la mayoría y, por tanto, de la división de poderes y de las funciones de control y garantía de la magistratura y del propio parlamento (p. 155).

Esto da lugar a dos tipos de absolutismos: el de la mayoría y el de los poderes económicos del mercado. Por otro lado y en segundo término, existe la democracia constitucional, que entiende a la democracia:

[...] como un sistema frágil y complejo de separaciones y de equilibrios entre poderes, de límites de forma y de sustancia a su ejercicio, de garantía de los derechos fundamentales y de técnicas de control y reparación contra su violación, respecto de la cual, la regla de la mayoría y la del mercado, valen tan solo si están sometidas a los derechos fundamentales y a las libertades (Ferrajoli, 2000, p. 159) (cursivas propias).

Dentro de esta comprensión, los límites del poder y el control constitucional sobre el poder estarían relacionados con el núcleo mismo de la democracia, con su elemento contramayoritario, que determina la esfera de lo indecidible por las mayorías y por la política:

[...] que designa no solamente el espacio o el territorio prohibido sino también el espacio o territorio obligado: no sólo lo que no puede ser decidido, sino también lo que no pude dejar de ser decidido, o sea, lo que debe ser decidido (Ferrajoli, 2008, p. 343). 
Ahí cabe ubicar los derechos de las personas LGBTI, minoritarios en el escenario de la democracia mayoritaria o plebiscitaria, dispuesta por el dominio tradicional de las estructuras de los discursos binarios de sexo, del clericalismo, del militarismo y del dominio del cuerpo desde la institución del registro de la vida de las personas en la sociedad letrada.

Las limitaciones de las mayorías, la esfera de lo indecidible y el núcleo duro de la democracia pueden ser ilustrados al considerar la sentencia de fondo proferida por la Corte Interamericana de Derechos Humanos (en adelante, la Corte Interamericana) en 2011, al decidir el caso Gelman contra Uruguay. Los hechos están relacionados con la desaparición y asesinato de los esposos Marcelo Ariel Gelman y María Claudia García Iruretagoyena de Gelman, ocurridos tras su detención en Buenos Aires el 24 de agosto de 1976, a manos de militares argentinos. De acuerdo con la Corte (2011):

[...] los hechos comenzaron a perpetrarse en colaboración con autoridades argentinas en un contexto de práctica sistemática de detenciones arbitrarias, torturas, ejecuciones y desapariciones forzadas perpetradas por las fuerzas de seguridad e inteligencia de la dictadura uruguaya, en el marco de la doctrina de seguridad nacional y de la Operación Cóndor (Corte IDH, 2011, párr. 44).

El contexto general del asunto se refería al convenio hecho por los militares de Chile, Argentina, Uruguay, Paraguay, Bolivia y Brasil alrededor de la Operación Cóndor, una política de Estado que operaría en tres áreas: la vigilancia política de disidentes, refugiados o exiliados; la ejecución de acciones encubiertas de contrainsurgencia y la comisión de acciones conjuntas de exterminio.

En el caso de Uruguay, como parte del proceso de restitución del régimen democrático, fue expedida la Ley 15848 del 22 de diciembre de 1996, de impunidad, allí llamada "de caducidad". En su Artículo 1 establece que "ha caducado el ejercicio de la pretensión punitiva del Estado respecto de los delitos cometidos hasta el 1 de marzo de 1985 por funcionarios militares y policiales". En 1988, la Suprema Corte de Justicia declaró la constitucionalidad de la ley de impunidad; sin embargo, fue sometida a referendo en el año 1989, pero no alcanzó la mayoría requerida para su derogación. Más adelante, el 19 de octubre de 2009, la Suprema Corte 
de Justicia de Uruguay declaró la inconstitucionalidad de los Artículos 1, 3 y 4 de esa Ley y resolvió su inaplicabilidad en el caso que fallaba. Este hecho animó la convocatoria a un segundo referendo en octubre de 2010, que tampoco fue exitoso, pues el pueblo uruguayo prefirió que siguiera la impunidad, que no hubiese justicia y que no se buscara la verdad. En este sentido, la Ley de caducidad continuó vigente.

En su raciocinio, la Corte Interamericana vinculó la existencia y aplicación de la Ley de caducidad con la violación de numerosos derechos, así como con la obligación estatal de someter su Derecho interno a las normas de la Convención, al precisar que ni siquiera las decisiones del pueblo ejercitadas por referendo tienen el poder de consumar la impunidad por la violación de los derechos humanos mediante leyes de amnistía, pues sobre esas decisiones también debe ser ejercido el control de convencionalidad, como límite de los poderes de las mayorías y garante de la realización de los principios democráticos:

239. La sola existencia de un régimen democrático no garantiza, per se, el permanente respeto del Derecho Internacional, incluyendo al Derecho Internacional de los Derechos Humanos, lo cual ha sido así considerado incluso por la propia Carta Democrática Interamericana. La legitimación democrática de determinados hechos o actos en una sociedad está limitada por las normas y obligaciones internacionales de protección de los derechos humanos reconocidos en tratados como la Convención Americana, de modo que la existencia de un verdadero régimen democrático está determinada por sus características tanto formales como sustanciales, por lo que, particularmente en casos de graves violaciones a las normas del Derecho Internacional de los Derechos, la protección de los derechos humanos constituye un limite infranqueable a la regla de mayorias, es decir, a la esfera de lo "susceptible de ser decidido" por parte de las mayorias en instancias democráticas, en las cuales también debe primar un "control de convencionalidad" (supra párr. 193), que es función y tarea de cualquier autoridad pública y no sólo del Poder Judicial. En este sentido, la Suprema Corte de Justicia ha ejercido, en el Caso Nibia Sabalsagaray Curutchet, un adecuado control de convencionalidad respecto de la Ley de Caducidad, al establecer, inter alia, que "el límite de la decisión de la mayoría reside, esencialmente, en dos cosas: la tutela de los derechos fundamentales (los primeros, entre todos, son el derecho a la vida y a la libertad personal, y 
no hay voluntad de la mayoría, ni interés general ni bien común o público en aras de los cuales puedan ser sacrificados) y la sujeción de los poderes públicos a la ley (Corte IDH, 2011, párr. 239) (cursivas propias).

Como se aprecia, los hechos de este caso y la decisión de la Corte Interamericana explicitan la relación existente entre la democracia, los derechos humanos, los límites de las mayorías, los límites del poder político, los límites del propio pueblo y los controles de legalidad y de convencionalidad, en la medida en que permiten preguntarse si el poder de las mayorías es tan grande como para permitir la consumación de la impunidad por los crímenes atroces y la negación de los derechos de las víctimas a la realización de la justicia, a saber la verdad de lo sucedido y a la reparación integral. En últimas, de lo que se trata es de saber si las mayorías pueden disponer de los derechos de las minorías, en este caso, de los derechos de las víctimas de los militares y de los civiles que los apoyaron durante el período de la dictadura.

\subsection{El control, las omisiones legislativas y convencionales $y$ los derechos de las personas LGBTI}

Como fue señalado, la falla estructural del sistema está en el incumplimiento de las obligaciones de regulación y garantía, que a su vez implican el incumplimiento de elementos nodales de la democracia constitucional, en la medida en que bajo el dominio de la democracia mayoritaria ha sido instalado un modelo que sacrifica los derechos de las minorías, entre las que se cuentan las personas LGBTI. Frente a esta situación deben ser reivindicados el valor y la importancia de la democracia social y de la democracia constitucional, mismas que tienen como argumento sustantivo al Derecho Constitucional que, conforme a la evidencia empírica, se muestra sensible a las circunstancias históricas de marginación y discriminación.

No resulta extraño que, en un medio como el colombiano, la Constitución Política, el Derecho Constitucional, el despliegue de la jurisdicción constitucional y su instrumento - la sentencia constitucional- se hubieran convertido en el único escenario de reconocimiento y protección de los derechos de las personas LGBTI. Prueba de ello son la jurisprudencia en 
vigor y las líneas de protección establecidas alrededor de los derechos de las parejas del mismo sexo, la familia diversa y las personas transexuales.

Es en este escenario en donde ha tenido lugar la construcción del concepto de omisión legislativa que, desde el punto de vista del control, puede dar lugar a la inconstitucionalidad por omisión o a la inconvencionalidad; genéricamente, hacen referencia a las omisiones, los silencios, las incurias o las inactividades del legislador que bloquean el reconocimiento y la protección de los derechos, situación que resulta contraria a la Constitución o a las convenciones internacionales, en particular, a la Convención Americana sobre Derechos Humanos.

Bazán (2014) trabaja el asunto desde la teoría del control y señala como punto de partida que la Constitución o la Convención Americana pueden ser violadas por acción, como acontece, por ejemplo, cuando se expide una ley de amnistía o de indulto por crímenes atroces o por omisión, como cuando el Congreso no expide la ley que desarrolla habeas corpus, que es una garantía que no puede ser limitada ni siquiera en los estados de excepción, expresamente reconocida por la Constitución y la Convención Americana.

Desde la anterior distinción, el autor ofrece una definición de la inconstitucionalidad por omisión e identifica tres elementos constitutivos (Bazán, 2014). Sostiene que aquella consiste:

[...] en la falta o insuficiencia de desarrollo de una disposición constitucional por el legislador, y de manera excepcional por el Poder Ejecutivo, cuando existe un mandato constitucional expreso al respecto y que de aquella inactuación total o actividad deficiente, mantenida durante un lapso irrazonablemente extenso, se derive una situación jurídica contraria a la Constitución (p. 45).

Dicho en términos más sencillos, la inconstitucionalidad por omisión es una figura que acontece cuando concurren los siguientes tres elementos:

a) Que exista una disposición constitucional que no haya sido desarrollada por el Congreso o que haya sido desarrollada de un modo insuficiente por el mismo, o sea, que el Congreso haya incumplido la obligación de regular un derecho o una institución. 
b) Que la falta de desarrollo legislativo y la incuria del Congreso se hayan mantenido durante un tiempo no razonable, es decir, que el incumplimiento de la obligación de regulación se mantenga o se haya prolongado.

c) Que de la falta de desarrollo legislativo se derive una situación contraria a la Constitución. Esto significa que la falta de regulación implique la violación de derechos fundamentales y que esa violación de derechos se haya mantenido.

La situación de las personas LGBTI en Colombia, incluidos los transexuales, configura una omisión legislativa de carácter inconstitucional. No en vano la Corte Constitucional se ha referido de manera reiterada al "déficit de protección" sobre las personas LGBTI y, por esta vía, a la violación de las obligaciones de regulación y garantía sobre sus derechos.

Al aplicar los criterios de Bazán (2014), se tiene, que el derecho a la igualdad establecido en el Artículo 13 de la Constitución no ha sido desarrollado por el Congreso de la República en el caso de los derechos de las personas LGBTI y de los transexuales, en una situación en donde no solo ha habido incuria y omisión, sino verdadera resistencia. En segundo lugar, resulta evidente que la falta de desarrollo legislativo del derecho a la igualdad se ha mantenido durante veinticinco años, a pesar de los esfuerzos hechos por la Corte Constitucional: durante la década del noventa, comenzó a reconocer los derechos de esas personas; en la de 2000 reconoció y protegió expresamente los derechos de las parejas del mismo sexo y durante la década del diez viene extendiendo el reconocimiento y la protección de esos derechos a los otros miembros de la comunidad LGBTI.

Se tiene en tercer término que la falta de regulación ha derivado en situaciones contrarias a la Constitución, como se evidencia en las diversas formas de violencia documentadas por la Comisión Interamericana: marginación, discriminación permanente, barreras al trabajo y al servicio de salud y control y dominio de su cuerpo, derivado del manejo de instrumentos como el registro civil o la libreta militar, por ejemplo.

La figura de la omisión legislativa ha tenido desarrollo por la Corte Constitucional de Colombia, que en algunos casos ha declarado la inconstitucionalidad por omisión. Para el efecto, la Corte ha diferenciado entre las omisiones legislativas relativas y las omisiones legislativas absolutas y ejerce 
control constitucional solo sobre las primeras. El Tribunal ha construido algo así como un test de omisiones legislativas que dan lugar a declaratorias de inconstitucionalidad por omisión, cuyos componentes son muy similares a los descritos por Bazán (2014). De tal carácter es el pronunciamiento contenido en la Sentencia C-209 de 2007, que examinó los derechos de las víctimas dentro del proceso penal y reiteró:

[...] quien alega la inconstitucionalidad de una norma, por existencia de una omisión legislativa relativa, tiene la carga de demostrar (i) que existe norma constitucional expresa que contemple el deber de expedir la norma que la desarrolle; (ii) que el Legislador omitió tal obligación, sin que mediara motivo razonable a pesar de que reguló parcialmente la misma materia; (iii) que la conducta omisiva propicia una desigualdad de trato injustificada entre los casos que están y los que no están sujetos a las consecuencias previstas por la norma (Corte Constitucional, 2007).

Cabe señalar que la violación de los derechos de las personas LGBTI y el incumplimiento de las obligaciones de regulación del Congreso han sido enfrentados por los jueces de la jurisdicción constitucional mediante mecanismos adicionales a los que ofrece la inconstitucionalidad por omisión, como la emisión de sentencias condicionadas, la emisión de exhortos y la emisión de órdenes de regulación a las autoridades administrativas, que son todo un avance por ahora dispuesto respecto al derecho a morir dignamente (Corte Constitucional, 2014), el derecho a la objeción de conciencia al servicio militar (Corte Constitucional, 2014) y los derechos de las personas transexuales, a propósito de las estructuras de dominio sobre el cuerpo que propician la violación permanente de los derechos de las personas LGBTI.

\section{Estructuras notorias de dominio sobre el cuerpo y la orientación de género}

Hasta aquí se ha señalado que las personas LGBTI son víctimas de violencia generalizada, desplegada con distintas intensidades en todo el continente; además, asume diversas variedades y manifestaciones, como la 
violencia física, social, por prejuicio, sexual correctiva y médica, que involucra otras formas de violencia desarrolladas en el servicio público de salud.

La indagación acerca de esas formas de violencia permitió identificar otra forma de violencia de carácter institucional, relacionada con el incumplimiento de las obligaciones de regulación y garantía que tienen los Estados respecto a los derechos humanos, en general, y de los derechos de los que son titulares las personas LGBTI, en especial. Se explicitó el incumplimiento de esas obligaciones y se censuró la actitud de numerosos órganos legislativos de la región, empecinados en la criminalización de las manifestaciones de género y de las sexualidades alternativas; esto condujo a temas mayores ligados a la noción de democracia constitucional, los límites del poder público y los límites del poder de las mayorías, ambos dentro de lo que Ferrajoli (2008) llama la esfera de lo indecidible.

En el caso colombiano, la evidencia empírica muestra que la violencia institucional, materializada en el incumplimiento de las obligaciones de regulación y la garantía de los derechos de las personas LGBTI se ha entronizado, hasta el punto de que el Congreso de la República niega sistemáticamente el reconocimiento y la protección de los derechos de esas personas y fuerza a los jueces de la jurisdicción constitucional a implementar los mecanismos de regulación y garantía, por medio de figuras como la modulación de las sentencias constitucionales, los exhortos, la declaración de omisiones legislativas y convencionales y las órdenes directas de reglamentación dadas a autoridades administrativas.

En atención a ese estado de cosas, la parte final de este escrito se pregunta por las estructuras que han avalado la resistencia del Congreso a admitir y garantizar los derechos de las personas LGBTI. Pueden ser identificadas la estructura del dominio clerical o religioso, la estructura del dominio militar y la estructura de dominio desde el registro en el escenario de la sociedad letrada.

\subsection{La estructura del dominio clerical o religioso sobre el cuerpo y la orientación de género}

Esta estructura es más que evidente; es histórica y corresponde a las condiciones de colonización del territorio por parte de los españoles y al establecimiento de la República bajo el patronato de la Iglesia católica y 
que ahora se comparte con diversas iglesias, cultos y sectas cristianas que se han extendido en el país.

Como en todos los casos de estructuras de dominio sobre el cuerpo, la sexualidad y la orientación de género, en el escenario de esas religiones domina la heteronormatividad, la cisnormatividad y los binarios de sexo y género. Concurre con el sistema de dogmas, creencias y sanciones en los que el homosexualismo, el lesbianismo y el transgenerismo son una desviación y un pecado.

Como se dijo, la estructura de dominio clerical y religioso sobre los cuerpos fue establecida desde el período de la Colonia y pasó a la República sin modificaciones sustantivas. Morigerada durante el período federal, resurgió con gran fuerza con la Constitución de 1886, que dispuso todo un programa del ejercicio del poder desde la vinculación de la Iglesia católica con el Estado, lo que impidió el desarrollo de una sociedad laica en Colombia.

El carácter confesional de aquella Constitución, además de evidente, fue expresado en sus normas, entre las que se destaca el Artículo 38: "Artículo 38. La Religión Católica, Apostólica y Romana, es la de la Nación; los poderes públicos la protegerán y harán que sea respetada como esencial elemento del orden social". Asimismo, el Artículo 41 sobre educación: "Artículo 41. La educación pública será organizada y dirigida en concordancia con la Religión Católica".

Sin embargo, el elemento central del establecimiento de la estructura de dominio sobre los cuerpos fue el Concordato, firmado el 13 de diciembre de 1887 en Roma. Desplegó su influjo normativo durante todo el siglo XX, como lo evidencia la Ley 35 de 1888, aprobatoria de ese tratado público; la Convención Adicional al Concordato, firmada en Roma el 20 de julio de 1892; la Ley 34 de 1892, aprobatoria de la Convención Adicional sobre el Concordato; la Ley 54 de 1924, aprobatoria de los Acuerdos derivados del canje de notas 27643 de febrero 27 de 1924, suscrito entre el secretario de Estado del Papa y el ministro plenipotenciario del Estado colombiano; la Convención sobre Misiones, de enero 29 de 1953; el segundo Concordato, firmado en Bogotá el 12 de julio de 1973; la Ley 20 de 1974, aprobatoria del tratado anterior; la sentencia de febrero 12 de 1897, proferida por la Corte Suprema de Justicia, por la que se inhibió de hacer control constitucional sobre el Concordato y su ley aprobatoria. 
Ahora bien, si eso acontecía en el plano normativo, el plano sustantivo no deja dudas acerca de la red de dominio que se instalaba, en tanto allí se previó que la Iglesia católica dominaría la vida espiritual y cultural de los indígenas, la familia, el matrimonio y el derecho de familia de los colombianos; que sus ministros y autoridades ostentarían calidades propias de servidores públicos; que dominaría toda la educación pública; que la formación religiosa católica sería obligatoria en los establecimientos oficiales de enseñanza primaria y secundaria; que recibiría donaciones, auxilios y dineros provenientes del presupuesto general de la Nación; que tendría exenciones tributarias; que habría gobierno civil y eclesiástico sobre asuntos del Estado y sobre asuntos de la religión; que el registro civil de las personas estaría por cuenta de la Iglesia católica; que la distribución del territorio estaría conforme a criterios derivados de la religión; que habría una Vicaría castrense, destinada a la "atención espiritual" de los miembros de las Fuerzas Armadas, de conformidad con normas y reglamentos dictados desde el Estado Vaticano; que los clérigos, religiosos y obispos tendrían fueros especiales de juzgamiento; que habría delitos específicos tipificados para la protección de la Iglesia católica y sus funcionarios; que la Iglesia católica manejaría el servicio público de los cementerios alrededor de los cuales se consumó la violación de más derechos fundamentales, puesto que los sacerdotes se negaron a enterrar a los suicidas, las prostitutas y los homosexuales, entre otras personas.

Ese sistema de dominación pervive aun después de la expedición de la Carta de 1991, como lo prueban las constantes manifestaciones de rechazo de los prelados de la Iglesia católica y de las cristianas en torno a los derechos reproductivos de las mujeres, de la interrupción voluntaria del embarazo, del derecho a la muerte digna y de los derechos de las personas LGBTI.

\subsection{La estructura del dominio militar sobre el cuerpo y la orientación de género}

La estructura del dominio militar sobre el cuerpo está muy vinculada a la estructura del dominio clerical y en ambas prevalecen los principios de heteronormatividad, cisnormatividad y los binarios de sexo y género. Esto es fácil de probar. La estructura militar siempre ha estado dominada por el 
binario de sexo: hasta hace muy poco, la actividad militar era en exclusiva masculina y sanciona el homosexualismo como conducta desviada. Con la reciente inclusión de las mujeres en el servicio, se ha comenzado a castigar al lesbianismo también como conducta desviada. En ambos casos, las normas establecen la homosexualidad y el lesbianismo como faltas disciplinarias con el retiro del servicio como sanción. Peor aún, la Corte Constitucional en sus primeras etapas y con el auspicio de José Gregorio Hernández, coadyuvó la violación de los derechos fundamentales, al negar el amparo aun en casos en los que miembros de la Policía habían practicado sexo homosexual en privado y avalar sanciones como la siguiente:

Artículo (sic) Primero: Retirar en forma absoluta y con nota de Mala Conducta de la Policía Nacional al. XXX, perteneciente a la Compañía Simón Bolívar, al establecerse plenamente que infringió el Reglamento de Disciplina para la Policía Nacional, Decreto 100 del 110189, en su libro II, Título III, Capítulo II Art. 121 DE LAS FALTAS CONSTITUTIVAS DE MALA CONDUCTA, numeral 46 "EJECUTAR ACTOS DE HOMOSEXUALISMO, hechos ocurridos el día 29-10-93, consistente en ejecutar actos que lesionan gravemente la moral y el prestigio y la disciplina de la Policía Nacional (Corte Constitucional, 1995) (cursivas propias).

Si bien la Corte Constitucional ha hecho la corrección doctrinal y protege ahora el derecho a la intimidad, a la identidad sexual y a la orientación de género, subsisten diversos instrumentos de dominio sobre el cuerpo, entre los que vale destacar el servicio militar y la libreta militar, que imponen cargas y barreras a los ciudadanos, en general, y a las personas LGBTI, en especial.

La obligación general de prestar servicio militar y la necesidad de tener libreta militar para acceder al trabajo o a la educación son violatorias de los derechos fundamentales. Además, el servicio militar es una de las actividades más inútiles y deformantes en la vida de una persona, inadecuada a la tarea de construir vida democrática. La norma vigente es la Ley 48 de 1993, "Por la cual se reglamenta el servicio de reclutamiento y movilización", cuyo Artículo 10 establece la obligatoriedad para los varones y la voluntariedad para las mujeres, así: 
Artículo 10. Obligación de definir la situación militar. Todo varón colombiano está obligado a definir su situación militar a partir de la fecha en que cumpla su mayoría de edad, a excepción de los estudiantes de bachillerato, quienes definirán cuando obtengan su título de bachiller. La obligación militar de los colombianos termina el día en que cumplan los cincuenta (50) años de edad.

Parágrafo. La mujer colombiana prestará el servicio militar voluntario, y será obligatorio cuando las circunstancias del país lo exijan y el Gobierno Nacional lo determine, en tareas de apoyo logístico, administrativo, social, cultural o de defensa de la ecología y el medio ambiente, y en general, de las actividades que contribuyan a la modernización y al desarrollo del país y tendrán derecho a los estímulos y prerrogativas que establece esta Ley no importando la modalidad en que se preste el servicio (cursivas propias).

Los Artículos 36 y 37 fijan las consecuencias y sanciones que sobrevienen por no "definir la situación militar" o por no obtener la libreta militar. En principio el Artículo 36 viola múltiples derechos e impide que las personas puedan ingresar al servicio público y obtener títulos profesionales, así:

Artículo 36. Modificado por el artículo 111 del Decreto 2150 de 1995. Los colombianos hasta los 50 años de edad, están obligados a definir su situación militar. No obstante, las entidades públicas o privadas no podrán exigir a los particulares la presentación de la libreta militar, correspondiéndoles a éstas la verificación del cumplimiento de esta obligación en coordinación con la autoridad militar competente únicamente para los siguientes efectos:

a. Celebrar contratos con cualquier entidad pública;

b. Ingresar a la carrera administrativa;

c. Tomar posesión de cargos públicos, y

d. Obtener grado profesional en cualquier centro docente de educación superior.

En segundo término, reitera la violación de los derechos fundamentales, al impedir a las personas trabajar en el sector privado, así:

Artículo 37. Prohibición vinculación laboral. Ninguna empresa nacional o extranjera, oficial o particular, establecida o que en lo sucesivo se 
establezca en Colombia, puede disponer vinculación laboral con personas mayores de edad que no hayan definido su situación militar.

La infracción a esta disposición se sancionará en la forma que más adelante se determinará.

La jurisdicción constitucional ha tenido que lidiar con ese cúmulo de cargas desproporcionadas que afectan en especial a las personas LGBTI. La Sentencia T-476 de 2014 presenta el caso de Grace Kelly Ramírez (su nombre transgénero), a quien la Secretaría de Integración Social de la Alcaldía Mayor de Bogotá le violó sus derechos fundamentales, al excluirla del proceso de selección para prestar servicios personales mediante contrato en esa Secretaría, por no tener libreta militar.

Los hechos señalan que el 26 de septiembre de 2013 Grace Kelly Ramírez, una mujer transgénero, allegó su hoja de vida a la Subdirección de asuntos LGBTI de la Secretaría de Integración Social de la Alcaldía Mayor de Bogotá, con el fin de participar en un proceso de contratación adelantado por esa entidad, para un sector de la población de mujeres transgénero. El 30 de octubre del mismo año, la Subdirección le notificó que no era posible su contratación, porque no aportó la copia de su libreta militar. Por la evidente violación de sus derechos fundamentales, la afectada propuso acción de tutela y el amparo fue negado por los jueces de instancia.

El caso fue seleccionado por la Corte Constitucional, la cual protegió los derechos fundamentales de la víctima y señaló:

[...] la obligación impuesta en el artículo 36 de la Ley 48 de 1993, es inaplicable a las personas que han construido su identidad como mujeres transgénero, en cuanto su identidad no corresponde al concepto de "varón" contenido en la disposición referida, con lo cual, en los procesos de selección y contratación que se adelanten en las entidades públicas y particulares no se podrá exigir la libreta militar a las personas transgeneristas (Corte Constitucional, 2014) (cursivas propias).

Poco después fue proferida la Sentencia T-099 de 2015, que es determinante, en tanto que forzó el cumplimento de un segmento de las obligaciones de regulación relacionadas con el servicio militar y la libreta militar de las personas transexuales. Los hechos muestran la situación de 
Gina, una persona que, aunque fisiológicamente nació hombre, empezó a considerarse una mujer desde los 12 años de edad; fue expulsada de su casa y se vio forzada a ejercer la prostitución, sin poder conseguir trabajo por la falta de la libreta militar. Más adelante, fue desplazada por las bandas criminales (Bacrim) hacia Bogotá junto con su madre; se inscribieron en el Registro Único de Víctimas (RUV) y como ayuda humanitaria obtuvieron un mercado y un subsidio de atención por un valor de $\$ 640.000$, por lo que tuvo que ejercer de nuevo la prostitución.

El 8 de mayo de 2014 sostuvo una reunión con el coronel Carrillo Rubio, con el fin de definir su situación militar. Este la remitió al Distrito Militar No. 59 en Soacha, en donde presentó un certificado del RUV con el fin de ser eximida del pago de la cuota de compensación y recibir su libreta militar. Sin embargo, no consiguió el documento, pues le informaron que debía pagar una multa de $\$ 1.300 .000$ "porque no se había presentado a tiempo hace diez años. En atención a estos hechos, presentó una acción de tutela contra la Dirección de reclutamiento y control de reservas del Ejército y pidió que se ordenara a la entidad expedir su libreta militar. Además, solicitó una reparación en abstracto, que se ordenara al Ejército establecer una ruta de atención especial para las personas transexuales y que se instara al Ministerio del Interior para que presentara y tramitara ante el Congreso un proyecto de ley de identidad de género que proteja los derechos constitucionales de las mujeres y hombres transexuales.

La Sala especializada en restitución de tierras del Tribunal Superior de Bogotá, en Sentencia del 5 de agosto de 2014, amparó sus derechos y ordenó al Ejército que expidiera y entregara la libreta militar sin imponer restricciones que atenten contra su identidad de género; también ordenó a la Unidad para la atención y reparación integral a las víctimas que hiciera una caracterización de Gina y que le entregara ayudas humanitarias y la indemnización administrativa. El caso fue seleccionado por la Corte Constitucional, que examinó la situación de la accionante desde las normas del DIDH y su propia jurisprudencia y fijó como tesis central del caso el siguiente enunciado:

111. La Sala concluye que la Dirección de Reclutamiento y Control de Reservas del Ejército Nacional violó los derechos fundamentales de la actora por hacerla destinataria de la Ley 48 de 1993 como a un varón -tal 
como la identifican sus documentos - a pesar de que ella se reconoce a símisma como una mujer transexual. En ese sentido no era procedente condicionar la expedición de su libreta militar al pago de una multa por no haberse presentado a regularizar su situación militar en tiempo. Efectivamente, la señora Gina Hoyos Gallego, en su condición de mujer transexual, no es destinataria de una norma dirigida a los varones colombianos, a pesar de que el nombre y género que aparecen en sus documentos de identidad sean masculinos. Sin duda, la identidad de género y la orientación sexual son conceptos altamente complejos, no se definen con base en un elemento aislado -como por ejemplo el nombre- y por ser una parte inherente de las personas, todo trato basado en los mismos es particularmente delicado y merece el máximo respeto. Ante posibles contradicciones entre los documentos oficiales y la identidad de género, la única forma digna para establecer esta última es manifestación de la auto percepción (Corte Constitucional, 2015) (cursivas propias).

Desde allí la Corte dispuso varias órdenes, entre las cuales sobresalen dos:

- Una orden directa de reglamentación dirigida al Ministerio de Defensa relacionada con los derechos de las personas transgénero y los mecanismos de reclutamiento

Sexto. ORDENAR al Ministerio de Defensa y al Comando General de las Fuerzas Armadas que, en un plazo máximo de dos (2) meses contados a partir de la notificación de la presente sentencia, desarrollen un protocolo de información y una campaña pedagógica en todos los distritos de reclutamiento del país para que, en caso de que nuevamente una mujer transgénero sea citada a regularizar su situación militar, ésta conozca plenamente los límites que tiene la Ley 48 de 1993 y la obligación que tiene la autoridad militar de no realizar ningún procedimiento que vulnere la dignidad, la autonomía, el libre desarrollo de la personalidad e igualdad de estas ciudadanas, en los términos señalados en esta providencia. Del mismo modo, deberá incluirse un mecanismo para el reclutamiento de los hombres transexuales que puedan ser sujetos de la Ley 48 de 1993 y deberá considerarse la posibilidad de que las mujeres transexuales gocen de garantías suficientes para prestar el servicio militar, cuando voluntariamente lo decidan, tal como les es permitido por la Ley (Corte Constitucional, 2015) (cursivas propias). 
- Una orden directa de iniciativa legislativa dirigida al Ministerio del Interior, que disponga la inclusión de asuntos relevantes dentro del proyecto

Séptimo. INSTAR al Ministerio del Interior a que, dentro del proceso de política pública que viene desarrollando para la presentación de un proyecto de Ley de Identidad de Género, incluya propuestas tendientes a remover los obstáculos que las personas transgénero tienen que enfrentar para la modificación de su identidad o de su sexo en los documentos de identidad y de registro civil. Particularmente, se recomienda incorporar mecanismos que: i) hagan posibles los cambios de sexo y nombre en los documentos de identidad y en el registro civil, con la simple declaración de parte ante notario público rendida por la persona que se autorreferencia como hombre o mujer transexual; ii) introduzcan la posibilidad de que las personas puedan no reconocerse a sí mismas dentro de alguno de los sexos binarios (masculino o femenino) con la incorporación de un sexo indeterminado en los documentos oficiales; iii) proscriban cualquier procedimiento judicial, notarial o médico que implique que las personas transexuales deban someterse a prácticas violatorias de su derecho a la dignidad humana e invasivas de su privacidad, intimidad y autonomía (Corte Constitucional, 2015) (cursivas propias).

Estas decisiones de la Corte remiten al tema del registro, otra de las estructuras históricas de dominación sobre las personas LGBTI, cuyas omisiones legislativas comienzan a ser suplidas desde las órdenes de los jueces constitucionales.

\subsection{La estructura de dominio sobre el cuerpo y la orientación de género desde el registro civil de las personas}

En Colombia, la norma reguladora en materia de registro civil de las personas y de inscripción del nombre y parentesco es el Decreto 1260 de 1970, "Por el cual se expide el Estatuto del Registro del Estado Civil de las Personas", modificado entre otras normas, por el Decreto 999 de 1988, "Por el cual se señala la competencia para las correcciones del registro del estado civil, se autoriza el cambio de nombre ante notario público, y se dictan otras disposiciones". 
Otras tres normas resultan decisivas: el Artículo 94, que permite el cambio de nombre por una sola vez:

Artículo 94. Escritura pública para sustituir, rectificar, corregir o adicionar realizada por el propio inscrito. El propio inscrito podrá disponer, por una sola vez, mediante escritura pública, la modificación del registro, para sustituir, rectificar, corregir o adicionar su nombre, todo con el fin de fijar su identidad personal. La mujer casada podrá proceder, por medio de escritura pública, adicionar o suprimir el apellido del marido precedido de la preposición de, en los casos en que ella lo hubiere adoptado o hubiere sido establecido por la ley.

El instrumento a que se refiere el presente artículo deberá inscribirse en el correspondiente registro civil del interesado, para lo cual se procederá a la apertura de un nuevo folio. El original y el sustituto llevarán notas de recíproca referencia.

Y los artículos 95 y 96, que disponen que las modificaciones sobre estado civil (¿y sexo?) requieran escritura pública o sentencia judicial, implicando como en el caso anterior, la apertura de un nuevo folio y anotaciones en el existente. Así se tiene:

Artículo 95. Modificación de una inscripción. Toda modificación de una inscripción en el registro del estado civil que envuelva un cambio de estado, necesita de escritura pública o decisión judicial firme que la ordena o exija, según la ley. [...]

Artículo 98. Decisiones judiciales que alteran o cancelan el registro. Las decisiones judiciales que ordenen la alteración o cancelación de un registro se inscribirán en los folios correspondientes, y de ellas se tomarán las notas de referencia que sean del caso y se dará aviso a los funcionarios que tengan registros complementarios.

De esta manera, se tiene que el régimen de registro del estado civil de las personas corresponde a normas expedidas por la Constitución de 1886, que era teocrática, clerical, autoritaria y provinciana. Por lo mismo, esas normas solo previeron la posibilidad de cambiar el nombre por una sola vez y no el registro del cambio de sexo e implican la creación de folios adicionales para las personas LGBTI, con anotaciones infamantes que impiden 
el acceso a derechos (como el trabajo, la salud) y vulneran el derecho a la intimidad. Frente a ese déficit de regulación y la violación de los derechos de los transexuales, la Corte Constitucional ha instituido reglas y órdenes de regulación en diversos fallos. Son relevantes las sentencias T-1033 de 2008 y T-063 de 2015 que, junto con la ya examinada Sentencia T-099 de 2015, dieron lugar a la histórica expedición del Decreto 1227 de 2015, "Por el cual se adiciona una sección al Decreto 1069 de 2015, Único reglamentario del sector Justicia y del Derecho, relacionada con el trámite para corregir el componente sexo en el Registro del Estado Civil".

Los hechos contenidos en la Sentencia T-1033 de 2008 refieren la situación de una persona de sexo biológico masculino que había tramitado y obtenido el cambio de nombre por otro de sexo femenino ante la Registraduría Nacional del Estado Civil, debido a su inconformidad con el sexo asignado al nacimiento. Ocurrió, según palabras del propio accionante, que con su nueva identidad de género:

[...] se vio abocado a una vida de prostitución y degradación personal que lo hizo reflexionar sobre su futuro al punto de decidir dejar atrás la vida que llevaba para procurar la conformación de una familia y la obtención de un trabajo digno (Corte Constitucional, 2008).

En virtud de los cambios que introdujera en su plan de vida, solicitó a la Registraduría un segundo cambio de nombre para restituir el masculino original, petición que le fue negada con base en lo dispuesto en el Artículo 94 del Decreto 1260 de 1970, que permite el cambio de nombre por una sola vez mediante escritura pública.

Dada la negativa, el afectado interpuso una acción de tutela que fue tramitada por la Sala Civil del Tribunal Superior del Distrito judicial de Cali. El 9 de noviembre de 2007 negó el amparo, porque consideró que no se había violado ningún derecho fundamental y que el Decreto 1260 de 1970 fijaba la posibilidad del cambio de nombre por una sola vez.

El acto fue seleccionado por la Corte Constitucional. Al resolver, aplicó la excepción de inconstitucionalidad y consideró que si bien el artículo 94 del Decreto 1260 de 1970 establecía una limitación razonable, en el caso concreto del accionante implicaba la violación de sus derechos fundamentales a la personalidad jurídica y al libre desarrollo de la personalidad, puesto 
que le impedía cumplir su identidad de género, que la Corte confundió en el fallo con la orientación sexual (Corte Constitucional, 2008). De esta manera, se ampararon los derechos de identidad de género de un transexual.

Este precedente fue reiterado en fallos posteriores, en especial en la Sentencia T-063 de 2015, que converge con las órdenes dispuestas en la Sentencia T-099 de 2015 y da lugar a la expedición del Decreto 1227 de 2015. Esta refiere la situación de Sara Valentina, quien mediante acción de tutela obtuvo, en febrero de 2014, una cirugía de reafirmación de sexo, mamoplastia y otros procedimientos necesarios para su tránsito de género. Tras el procedimiento, Sara acudió a la Notaría 12 de Medellín para hacer el cambio de nombre y de sexo en su registro civil de nacimiento y demás documentos de identidad. Allí se le indicó que podía cambiar el nombre, pero que para el cambio de sexo era necesaria una orden judicial. Sara Valentina tenía sexo y apariencia femenina, mientras en el registro civil y demás documentos figuraba con nombre masculino, situación que precipitó toda suerte de discriminaciones laborales y sociales: nadie le dio empleo, no pudo homologar una licencia de aviación obtenida en Miami, tampoco pudo presentarse a una escuela de aviación en Antioquia ni ejercer sus derechos políticos; además, fue objeto de burla.

En ese estado de cosas interpuso una acción de tutela por el amparo de sus derechos fundamentales, la corrección del sexo inscrito en su registro civil de nacimiento y demás documentos de identidad como la cédula de ciudadanía y el pasaporte colombiano y el cambio del número de su cédula de ciudadanía para que concordara con las nomenclaturas femeninas, todo ello sin tener que acudir a un proceso de jurisdicción voluntaria. La Sala Civil del Tribunal Superior de Medellín conoció del proceso y, mediante providencia de mayo 21 de 2014, declaró la improcedencia del amparo, puesto que existía un procedimiento adecuado que debía ser adelantado ante el juez de familia, con "comprobación científica" del aspecto que se modificaba.

Seleccionado el caso por la Corte Constitucional se formuló la siguiente pregunta: ¿se vulneran los derechos a la personalidad jurídica, dignidad e identidad de género y sexual al exigirle a una persona transgenerista que adelante un proceso de jurisdicción voluntaria a efectos de modificar el sexo inscrito en el registro civil de nacimiento y demás documentos de identidad? 
Como premisa central, la Corte reiteró su jurisprudencia en torno al derecho a la dignidad humana, al libre desarrollo de la personalidad y al reconocimiento de la personalidad jurídica como fuentes básicas de la identidad sexual y de género. Además, reconstruyó la legislación que regula el registro del estado civil de las personas e hizo énfasis en la Ley 1564 de 2012, "Por medio de la cual se expide el Código General del Proceso y se dictan otras disposiciones", cuyo Artículo 577, numeral 11, mantiene la norma vigente en el anterior Código de Procedimiento Civil, según la cual se sujetarán al procedimiento de jurisdicción voluntaria [...] "la corrección, sustitución o adición de partidas de estado civil o del nombre, o anotación del seudónimo en actas o folios de registro de aquel" (cursivas propias), mientras el Artículo 617 del mismo Estatuto establece:

[...] sin perjuicio de las competencias establecidas en este Código y en otras leyes, los notarios podrán conocer y tramitar, a prevención, de los siguientes asuntos: [...] 9. De las correcciones de errores en los registros civiles. Parágrafo. Cuando en estos asuntos surjan controversias o existan oposiciones, el trámite se remitirá al juez competente.

La Corte constató que las autoridades notariales y de registro han dado lugar a una práctica según la cual una persona transgénero solo puede solicitar el cambio de sexo mediante un proceso de jurisdicción voluntaria, en el que demuestre con pruebas médicas que ha tenido cambios físicos y psicológicos, en especial genitales. Todo esto, en opinión de la Corte, implica la imposición de barreras inconstitucionales (Corte Constitucional, 2015), puesto que la actuación judicial requiere la presencia de un abogado; implica la demora de varios meses durante los cuales se presenta discriminación y victimización de la persona; el proceso de jurisdicción se convierte en un ejercicio de peritajes e intervenciones sobre el cuerpo; la persona ve comprometida su intimidad, al tener que hacer públicas las emociones y las decisiones más personales; constituye un trato discriminatorio respecto a las personas cisgénero, a quienes se les permite efectuar la misma corrección mediante escritura pública. Concluyó que la obligación de acudir a la jurisdicción para hacer la corrección del sexo inscrito en el registro civil resultaba innecesaria y gravosa y constituía un trato discriminado frente a 
las personas cisgénero, quienes podían corregir ese dato sin proceso judicial (Corte Constitucional, 2015).

El poder del fallo se encuentra en las órdenes dadas a la Notaría y a la Registraduría Nacional del Estado Civil, que conllevan una modificación en las prácticas discriminatorias de los notarios y de los registradores, en tanto suprimen el requisito del proceso de jurisdicción voluntaria en los casos de cambio de sexo y una modificación en la documentación y en la manera de efectuar el registro civil en esos casos. La orden decisiva se encuentra en el segundo punto resolutivo:

Segundo. ORDENAR a la Notaría Doce del Círculo de Medellín que en el término de cuarenta y ocho (48) horas contado a partir de la notificación de esta providencia, por medio de escritura pública protocolice el cambio de nombre y la corrección del sexo que consta en el registro civil de nacimiento de la accionante, de modo tal que coincida con el nombre (Sara Valentina López Jiménez) y el sexo (femenino) con el que ella se identifica. Una vez efectuado dicho trámite, deberá enviar copia de la escritura pública a la Registraduría Nacional del Estado Civil quien deberá efectuar la modificación del registro civil y entregar una copia del mismo corregido a la accionante. Así mismo, la Registraduría deberá adoptar todas las medidas necesarias para garantizar la reserva del primer registro, que solo podrá ser consultado por la actora, por orden judicial que disponga su publicidad en un caso concreto, o por parte de las autoridades públicas que lo requieran para el ejercicio de sus funciones (Corte Constitucional, 2015).

Con base en lo dispuesto en ese fallo, el Gobierno nacional procedió a la histórica expedición del Decreto 1227 de 2015, que establece las reglas que deben seguir los notarios y registradores para efecto de la corrección del componente sexo en el registro civil de nacimiento.

Expedida la norma, el registrador nacional del Estado civil dispuso lo necesario para su aplicación, cosa que no ocurrió con algunos notarios empeñados en impedir la realización de los derechos de las personas LGBTI, como lo evidencia su negativa a permitir los matrimonios de parejas del mismo sexo, pese al reconocimiento hecho por la Corte Constitucional en la Sentencia C-577 de 2011. Expresaron toda suerte de objeciones e inconvenientes ante los medios de comunicación e incluso expidieron 
un documento denominado Memorando No. 1153 de julio 3 de 2015, a nombre de la Unión Colegiada del Notariado Colombiano. En él, bajo el cuento de establecer una "recomendación o sugerencia", introducen interpretaciones y reglamentaciones encaminadas a erigirse como una nueva barrera para la realización de los derechos de las personas LGBTI; eso sí, señalan muy amañadamente al final del texto:

La Unión Colegiada del Notariado Colombiano "UCNC", pretende con el presente memorando informativo, dar claridad sobre el tema de la corrección del Registro Civil a la cual se refiere el Decreto 1227 de 2015, advirtiendo que no se trata de una "Instrucción" de la institución para sus notarios y, por lo tanto, que ninguna de las partes de su contenido es obligatoria (Unión Colegiada del Notariado Colombiano [UCNC], 2015).

Esta actitud de los notarios no solo ratifica la existencia de las estructuras de dominio sobre el cuerpo y la orientación de género, sino que advierte acerca de la dificultad de su remoción en Colombia.

\section{Referencias}

Abramovich, V. y Courtis, C. (2006). El umbral de la ciudadanía. El significado de los derechos sociales en el Estado social constitucional. Buenos Aires: Estudios del Puerto. Arango, R. (2012). Democracia social. Un proyecto pendiente. México D. F.: Fontamara. Bazán, V. (2014). Control de las omisiones inconstitucionales e inconvencionales. Bogotá: Konrad Adenauer Stiftung (KAS).

Cassagne, J. (2009). El principio de legalidad y el control judicial de la discrecionalidad administrativa. Buenos Aires: Marcial Pons.

Colombia, Corte Constitucional. (1995). Sentencia C-037 de 6 de febrero de 1995. M. P. José Gregorio Hernández.

Colombia, Corte Constitucional. (2007). Sentencia C-209 de 21 de marzo de 2007. M. P. Manuel José Cepeda Espinosa.

Colombia, Corte Constitucional. (2008). Sentencia T-1033 de 28 de marzo de 2008. M. P. Rodrigo Escobar Gil.

Colombia, Corte Constitucional. (2011). Sentencia C-577 de 26 de julio de 2011. M. P. Gabriel Eduardo Mendoza Martelo. 
Colombia, Corte Constitucional. (2014). Sentencia T-455 de 7 de julio de 2014. M. P. Luis Ernesto Vargas.

Colombia, Corte Constitucional. (2014). Sentencia T-476 de 9 de julio de 2014. M. P. Alberto Rojas.

Colombia, Corte Constitucional. (2014). Sentencia T-970 de 15 de diciembre de 2014. M. P. Luis Ernesto Vargas.

Colombia, Corte Constitucional. (2015). Sentencia T-063 de 13 de febrero de 2015. M. P. María Victoria Calle Correa.

Colombia, Corte Constitucional. (2015). Sentencia T-099 de 10 de marzo de 2015. M. P. Gloria Stella Ortiz Delgado.

Comisión Interamericana de Derechos Humanos. (2015). Violencia contra personas lesbianas, gays, bisexuales, trans e intersex en América. Recuperado de http://www. oas.org/es/cidh/informes/pdfs/ViolenciaPersonasLGBTI.pdf

Corte Interamericana de Derechos Humanos. (2011). Sentencia de fondo y reparaciones. Caso Gelman contra Uruguay.

Ferrajoli, L. (2000). El garantismo y la filosofía del derecho. Bogotá: Fundación Fes

Ferrajoli, L. (2008). La esfera de lo indecidible y división de poderes. Estudios Constitucionales, 6(1), pp. 337-343.

Principios de Yogyakarta. (2007). Principios sobre la aplicación de legislación internacional de los derechos humanos en relación a la orientación sexual y la identidad de género. Recuperado de http://www.yogyakartaprinciples.org/principles_sp.pdf Quinche, M. y Peña, R. (2013). El derecho judicial de la población LGBTIy de la familia. Bogotá: Legis.

Unión Colegiada del Notariado Colombiano [UCNC]. (2015). Memorando No. 1153. Recuperado de http://www.unioncolegiadadelnotariadocolombiano. com/sitio/sites/default/files/1153\%20Notarios\%20del\%20pa\%C3\%ADs\%20 \%20Componente\%20Sexo.pdf 